\title{
Midsummer deficit irrigation of alfalfa as a strategy for providing water for water-short areas
}

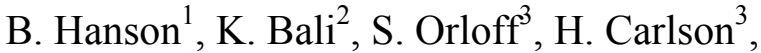 \\ B. Sanden ${ }^{4} \&$ D. Putnam \\ ${ }^{1}$ Dept. of Land, Air and Water Resources, University of California, \\ Davis, USA \\ ${ }^{2}$ University of California Cooperative Extension, Imperial County, USA \\ ${ }^{3}$ University of California Cooperative Extension, Siskiyou County, USA \\ ${ }^{4}$ University of California Cooperative Extension, Kern County, USA \\ ${ }^{5}$ Dept. of Plant Sciences, University of California, Davis, USA
}

\begin{abstract}
Alfalfa is California's single largest agricultural water user due to its large acreage and long growing season. As a result, interest exists in midsummer deficit irrigation (no irrigation in July, August, and September) of alfalfa in water-rich areas to provide water for water-short areas with the amount of transferred water equal to the difference in the evapotranspiration (ET) between fully-irrigated and deficit irrigated alfalfa. However, little data exists on the ET of midsummer deficit-irrigated alfalfa. Commercial fields were selected for fully-irrigated and deficit-irrigated irrigation treatments of alfalfa. The fullyirrigated alfalfa was irrigated according to the irrigator's normal practices. The deficit irrigation treatments were no irrigation in July through to September. Alfalfa ET was measured using the eddy covariance and surface renewal energy balance methods. Deficit irrigation of alfalfa during the midsummer reduced both ET and yield. The amount of reduction, however, was very site-specific. The Davis site showed the largest reduction in ET $(198 \mathrm{~mm})$, while the other sites showed much smaller reductions (5 to $62 \mathrm{~mm}$ ).
\end{abstract}

Keywords: alfalfa, evapotranspiration, irrigation. 


\section{Introduction}

Alfalfa is California's single largest agricultural water user due to the amount grown, typically about 405,000 ha, and its long growing season. Thus, interest exists in midsummer deficit irrigation (no irrigation in July, August, and September) of alfalfa to provide water for transfer from water-rich areas such as the Sacramento Valley to water-short areas such as the San Joaquin Valley and southern California. In theory, the amount of water available for transfer would equal the difference in the evapotranspiration (ET) between fully-irrigated and deficit irrigated alfalfa. This midsummer deficit irrigation strategy maintains the relatively high yields of the first part of the year and eliminates irrigations during the summer when yields are small and quality is poor.

Studies have shown that midsummer deficit irrigation reduces crop yield [1-5]. Different alfalfa yield responses to deficit irrigation were found with the main factors contributing to the yield response to be soil texture and climate. These studies also showed that while no irrigation during the midsummer reduced the alfalfa yield, it generally did not stop all plant growth, and as a result, some level of evapotranspiration occurred. Little information exists on differences in midsummer ET between fully-and deficit-irrigated alfalfa. This study investigated the effect of midsummer deficit irrigation on yield and evapotranspiration in commercial alfalfa fields at sites throughout California, a major alfalfa production state in the USA.

\section{Methods and materials}

\subsection{Experiment design}

Sites were selected near Davis (southern end of the Sacramento Valley), Tulelake (Intermountain area of northern California), El Centro (Imperial Valley of southern California), Scott Valley (Intermountain area of northern California), and in Kern County ( southern end of the San Joaquin Valley) for fully-irrigated and deficit-irrigated treatments of alfalfa. These locations were selected to obtain a wide range of climatic and field conditions for this experiment. Field elevations ranged from $-2 \mathrm{~m}$ to $1,220 \mathrm{~m}$; maximum midsummer air temperatures ranged from 22 to $45{ }^{\circ} \mathrm{C}$; minimum midsummer air temperatures were 5 to $25{ }^{\circ} \mathrm{C}$; minimum relative humidity ranged from 10 to 40 percent; and soil types were loam to clay. All sites were in commercial fields except the Tulelake site, which was located at the University of California Intermountain Research and Extension Center. The irrigation method was border (flood) irrigation at the Davis, El Centro, and Kern County sites and was sprinkle irrigation at the Tulelake and Scott Valley sites. The fully-irrigated alfalfa was irrigated according to the irrigator's normal practices. Deficit irrigation treatments at each site consisted of a dedicating a section of the field for which no irrigation occurred during the midsummer.

The field-scale approach was used instead of a randomized replicated experiment to obtain the field-wide conditions experienced by commercial 
agriculture and because a randomized replicated experimental design was not practical in the commercial fields.

\subsection{Measurements}

Alfalfa evapotranspiration (ET) was determined using the surface renewal (SR) energy balance method [6] in both fully irrigated and deficit irrigated treatments at all sites. Eddy covariance (EC) energy balance systems (Campbell Scientifc, Inc.) [7] were also installed at the Scott Valley and El Centro fully irrigated sites and used to calculate the ET of the fully irrigated treatments at those sites. Sensible heat data from the EC systems were used to calibrate the SR method. The uncalibrated sensible heat flux determined by the SR system must be corrected for unequal heating between the ground and the measurement height using independent measurements of sensible heat flux such as the EC data.

Alfalfa yield and quality were determined by machine-harvesting a predefined area at all sites except the El Centro site. At this site, hand-harvested plots were used to determine yield in both fully and deficit irrigated treatments. Soil water potential was measured with Watermark ${ }^{\circledR}$ electrical resistance blocks (Irrometer, Inc.) installed in both fully and deficit irrigated treatments.

\subsection{Instrumentation}

Sensors of the eddy covariance system were a CSAT3 sonic anemometer (Campbell Scientific, Inc.), four Hukseflux self-calibrating soil heat flux plates installed at $8 \mathrm{~cm}$ deep, two sets of spatially averaging soil temperature probes installed at 2 and $6 \mathrm{~cm}$ deep (Campbell Scientific, Inc.), two CS616 soil water sensors (Campbell Scientific, Inc.) installed $2.5 \mathrm{~cm}$ deep, and a Q7.1 net radiometer (Radiation and Energy Balance Systems, Inc.). The sensors were connected to a CR5000 data logger (Campbell Scientific, Inc.).

Sensors of the surface renewal system were a Q7.1 net radiometer, two soil heat flux plates (Radiation and Energy Balance Systems, Inc.), one set of spatially averaging soil temperature probes, and two fine wire thermocouples (0.076 mm diameter) (Campbell Scientific, Inc.) mounted about $1.5 \mathrm{~m}$ above the ground surface to measure air temperature. The sensors were connected to either a CR23X, a CR10X, or a CR1000 data logger (Campbell Scientific, Inc.), depending on the site, which recorded high frequency temperature data and low frequency data of other variables. Data archiving and processing to determine the uncalibrated sensible heat flux density is described in Snyder et al. (1996).

Sensible heat is transported in the vertical direction by upward and downward wind velocities, called eddies. The eddy covariance energy balance method used in this study calculates the sensible heat fluxes by measuring both vertical wind velocities and air temperatures using the CSAT3 sonic anemometer. The instantaneous deviations of wind velocity and temperature from the mean are determined, and the covariance of these deviations is used to calculate the sensible heat flux over the desired averaging period. At the same time, measurements of net radiation and soil heat flux are also made. The latent heat 
flux is calculated as net radiation minus the sum of the sensible heat and soil heat fluxes. The daily cumulative latent heat flux, converted to $\mathrm{mm} \mathrm{d}^{-1}$, is the ET.

The surface renewal method is a less expensive method for measuring sensible heat fluxes. The theory is that high frequency temperature data above and within a plant canopy has a ramp-like structure over time that occurs when an air parcel sweeps from above to the surface. Energy transfer between the air and canopy causes heating or cooling of the air while at the surface. The air parcel is then ejected from the surface and replaced by a new air parcel sweeping down from above. The sensible heat flux is directly related to the temperature change rate with time. Information of the surface renewal method is available on the website biomet.ucdavis.edu/SR.zip.

\section{Results and discussion}

\subsection{El Centro}

Daily ET of the fully-irrigated treatment (determined from the EC system) increased from about $1 \mathrm{~mm} \mathrm{~d}^{-1}$ at the beginning of 2007 to maximum values of 10 to $12 \mathrm{~mm} \mathrm{~d}^{-1}$ in June, and then decreased to about $1 \mathrm{~mm} \mathrm{~d}^{-1}$ at the end of the year (fig. 1A). Just after a harvest, ET decreased to values of 1 to $2 \mathrm{~mm} \mathrm{~d}^{-1}$. Seasonal ET was 1,379 $\mathrm{mm}$.

Deficit irrigation started at the end of June. A trend of decreasing ET over time occurred for the deficit treatment with ET values smaller than those of the fully-irrigated treatment. After DOY286, ET of both treatments was similar. ET of the fully irrigated and deficit irrigate treatments between DOY167 and 271 (considered to be the period of deficit irrigation) were 514 and $452 \mathrm{~mm}$, respectively. The difference was $62 \mathrm{~mm}$.

During the midsummer growth periods, daily cumulative net radiation values, expressed as an equivalent evaporation rate in $\mathrm{mm} \mathrm{d}^{-1}$, were smaller than the daily ET. At those times, the sensible heat flux was towards the ground surface, indicating an advective heat source contribution to the evapotranspiration which caused the daily ET to exceed the daily cumulative net radiation. The sensible heat flux direction was away from the ground surface just after a harvest due to heating of the ground surface as a result of the reduced canopy coverage.

Three harvests (July 24, September 24, and December 12) occurred after the start of deficit irrigation. Yields of the fully-irrigated alfalfa, based on hay samples, were $2.78,1.39$, and $1.81 \mathrm{Mg} \mathrm{ha}^{-1}$ for the respective harvest dates, while the deficit-irrigated respective yields were $2.17,0$, and $1.66 \mathrm{Mg} \mathrm{ha}^{-1}$.

\subsection{Kern County}

ET values ranged from about $1 \mathrm{~mm} \mathrm{~d}^{-1}$ at the start of the measurement period to generally between 6 to $8 \mathrm{~mm} \mathrm{~d}^{-1}$ during the midsummer (data not shown). However, values between 8 and $10 \mathrm{~mm} \mathrm{~d}^{-1}$ occurred in May and June. Cumulative ET as of October 12 was $1,346 \mathrm{~mm}$. 

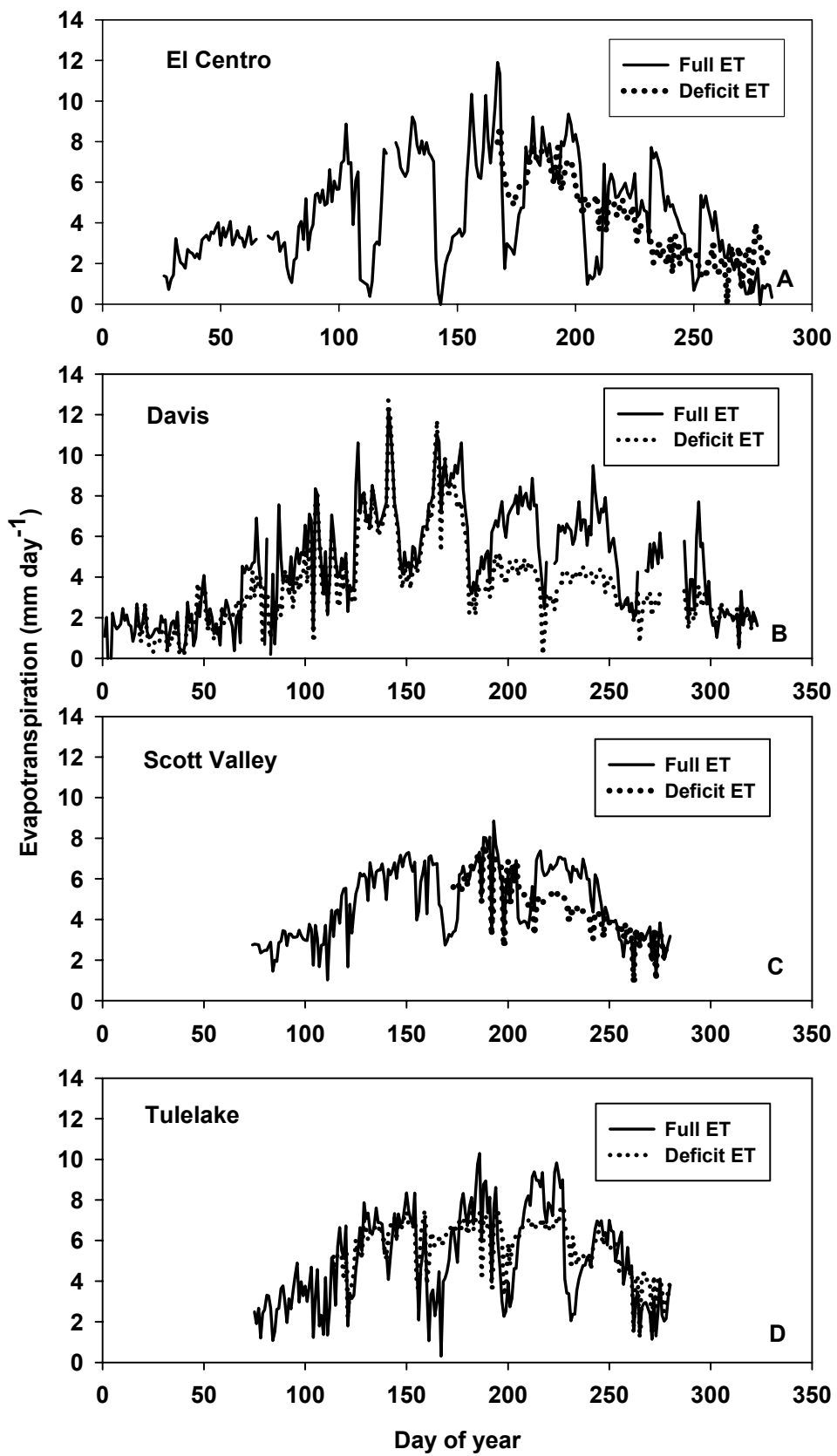

Figure 1: Evapotranspiration of fully-irrigated and deficit-irrigated alfalfa at four sites in California. 
Deficit irrigation, which occurred in August, had a slight effect on daily ET. Between August 10 and September 14, cumulative ET of the fully and deficit irrigated treatments was 191 and $155 \mathrm{~mm}$, respectively, and the ET difference was $36 \mathrm{~mm}$. The yield loss was $1.90 \mathrm{Mg} \mathrm{ha}^{-1}$.

\subsection{Davis}

Daily alfalfa ET ranged from smaller than $2 \mathrm{~mm} \mathrm{~d}^{-1}$ for the first 50 days of 2007 to values greater than $8 \mathrm{~mm} \mathrm{~d}^{-1}$ during June (fig. 1B). Just after harvest, ET levels ranged between 2 and $4 \mathrm{~mm} \mathrm{~d}^{-1}$. Seasonal ET was 1,520 $\mathrm{mm}$.

Deficit irrigation was imposed at the end of June. Maximum ET of the deficit treatment for the first growth period following initiation of deficit irrigation was between 4 and $5 \mathrm{~mm} \mathrm{~d}^{-1}$ compared to 7 to $8 \mathrm{~mm} \mathrm{~d}^{-1}$ for the full irrigation treatment (fig. 1B). ET of the deficit irrigation treatment continued to decrease over time to values of about $3 \mathrm{~mm} \mathrm{~d}^{-1}$ by DOY270. After DOY300, similar ET values occurred for both treatments. Cumulative ET between DOY182 and DOY300 (period of deficit irrigation) was $534 \mathrm{~mm}$ for full irrigation and 335 $\mathrm{mm}$ for deficit irrigation. The ET difference was $198 \mathrm{~mm}$.

Yield per harvest of full irrigation varied from a maximum of $4.64 \mathrm{Mg} \mathrm{ha}^{-1}$ for the June 26 harvest (just prior to the start of deficit irrigation) to a minimum of $2.68 \mathrm{Mg} \mathrm{ha}^{-1}$ for the October 26 harvest (last 2007 harvest). Yields between the full irrigation and deficit irrigation areas of the field were not statistically different for each harvest prior to the start of deficit irrigation at a level of significance of $0.05(\mathrm{P}=0.279$ to 0.598$)$. Yields during the period of deficit irrigation were 0.45 to $0.91 \mathrm{Mg} \mathrm{ha}^{-1}$, statistically different from those of the full irrigation treatment $(\mathrm{P}=0.0001$ to 0.0008$)$.

\subsection{Scott valley}

ET values at the start of the measurement period were between 2 and $3 \mathrm{~mm} \mathrm{~d}^{-1}$, but increased to between 3 and $4 \mathrm{~mm} \mathrm{~d}^{-1}$ by DOY89 (fig. 1C), and reached maximum values of nearly $8 \mathrm{~mm} \mathrm{~d}^{-1}$ on DOY188 to DOY181. ET just after harvest ranged between 3 and $4 \mathrm{~mm} \mathrm{~d}^{-1}$. The seasonal ET was $990 \mathrm{~mm}$.

Deficit irrigation started after the first harvest (DOY174). ET of both treatments was similar until DOY203, at which time the second harvest occurred. ET of the deficit irrigation treatment during the third growth period was considerably smaller than that of the full irrigation treatment, with values between 4 and $5 \mathrm{~mm} \mathrm{~d}^{-1}$ compared to 6 to $7 \mathrm{~mm} \mathrm{~d}^{-1}$ for the full irrigation. After about DOY246, similar ET values occurred for both treatments. Cumulative ET during the deficit irrigation period of DOY210 to 246 was $227 \mathrm{~mm}$ and $170 \mathrm{~mm}$ for the deficit and full irrigation treatments, respectively. The ET difference was $57 \mathrm{~mm}$.

Yields of the second harvest of the full and deficit irrigation treatments were 3.90 and $3.05 \mathrm{Mg} \mathrm{ha}^{-1}$, respectively, not statistically different at a level of significance $=0.05(\mathrm{P}=0.119)$. Yields of the third harvest were 2.15 and 0.65 $\mathrm{Mg} \mathrm{ha}{ }^{-1}$ for the respective treatments, which were statistically different $(\mathrm{P}=$ 0.0207). 


\subsection{Tulelake}

ET values at the start of the measurement period were between 2 and $3 \mathrm{~mm} \mathrm{~d}^{-1}$ and increased over time to values between 8 and $10 \mathrm{~mm} \mathrm{~d}^{-1}$ during the second and third growth periods, after which ET decreased to values between 1 and 4 $\mathrm{mm} \mathrm{d}^{-1}$ at the end of the measurement period (fig. 1D). Seasonal ET was 1044 $\mathrm{mm}$.

Deficit irrigation started at the beginning of the second growth period. Little difference in cumulative ET was found between the fully and deficit irrigated treatments during the deficit irrigation period (DOY176-280), with values of 594 $\mathrm{mm}$ and $589 \mathrm{~mm}$ for the respective treatments. The ET difference was $5 \mathrm{~mm}$.

Similar yields occurred for both treatments (data not shown). Yield differences for all harvests were not significant at a level of significance $=0.05$ $(\mathrm{P}=0.094$ to 0.530$)$.

At this site, little treatment differences were found in both ET and yield. The contributing factor for this behavior is shallow ground water with a water table depth of about $1 \mathrm{~m}$, based on historical experience. This, coupled with the fine texture soil, resulted in sufficient upward flow of ground water to satisfy the ET requirements of the deficit irrigated treatment.

\section{Conclusions}

Deficit irrigation of alfalfa during the midsummer reduced both ET and yield. The amount of reduction was very site-specific. The Davis site showed the largest reduction in ET $(198 \mathrm{~mm})$, while the other sites showed much smaller reductions ( 5 to $62 \mathrm{~mm}$ ). The Davis reduction was similar to that of the previous two years of experiments. It was expected that larger ET differences would have occurred at the Kern County and El Centro sites than were measured this year. A reason for the Kern County response may have been the soil type, which has a very high soil moisture retention capacity. This capacity appears to have been able to maintain high ET rates during periods of deficit irrigation. For the El Centro site, the effect of heat stress on alfalfa may have played a role in the ET differences between two treatments.

The seasonal measured ET values at the Davis and Kern County sites (as of October 12) were similar to the historical seasonal ET of 1,219 to 1,244 $\mathrm{mm}$. The seasonal measured ET values at the Scott Valley and Tulelake sites were greater than the historical seasonal ET of $838 \mathrm{~mm}$. For the El Centro site, the seasonal ET of $1,379 \mathrm{~mm}$ was considerably smaller than the historical ET of $1,930 \mathrm{~mm}$.

We conclude that it is neither feasible nor practical to base the amount of water available for transfer elsewhere on ET differences of alfalfa. There was no consistency in these differences between sites, reflecting the site specific characteristics. Also, basing the water transfer amount on ET differences penalizes the growers since the alfalfa growth during the period of deficit irrigation was due to soil moisture supplied by previous irrigations, for which growers were charged by the irrigation or water district. The exception was the Tulelake site, where shallow ground water contributed to the ET of the deficit irrigated treatment. 


\section{References}

[1] Frate, C.A., Roberts, B.A., Marble, V.L., 1991. Imposed drought stress has no long-term effect on established alfalfa. California Agriculture 45(3), 3336.

[2] Guitjens, J.C., 1993. Alfalfa irrigation during drought. Journal of Irrigation and Drainage Engineering 119(6), 1092-1098.

[3] Ottman, M.J., Tickes, B.R., Roth, R.L., 1996. Alfalfa yield and stand response to irrigation termination in an arid environment. Agronomy Journal 88, 44-48.

[4] Putnam, D., Takele, E., Kallenback, R., Graves, W., 2000. Irrigating alfalfa in the Low Desert: Can Summer Dry-down be Effective for Saving Water in Alfalfa? Report submitted to the Bureau of Reclamation (USDI), Yuma, Arizona.

[5] Robinson, F.E., Teuber, L.R., Gibbs, L.K., 1994. Alfalfa Water Stress Management During Summer in Imperial Valley for Water Conservation. Desert Research and Extension Center, El Centro, CA.

[6] Snyder, R.L., Spano, D., Paw U, K.T., 1996. Surface Renewal analysis for sensible and latent heat flux density. Boundary-Layer Meteorol. 77, 249266.

[7] Tanner, B.D., Tanner, M.S., Dugas, W.A., Campbell, E.C., Bland, B.L., 1985. Evaluation of an operational eddy correlation system for evapotranspiration measurements. American Society of Agricultural Engineers National Conference on Advances in Evapotranspiration, December 16-17, 1985. Chicago, IL. 